\title{
Variations in watchkeeping performance as a function of the rate and duration of visual signals'
}

\author{
JOEL S. WARM, UNIVERSITY OF CINCINNATI, MICHEL LOEB, UNIVERSITY OF LOUISVILLE, \\ AND EARL A. ALLUISI, ${ }^{2}$ PERFORMANCE RESEARCH LABORATOR Y, UNIVERSITY OF LOUISVILLE
}

This study was designed to assess the relative effects on watchkeeping performance of five signal durations 10.5 , $1.0,2.0,4.0$, and $8.0 \mathrm{sec})$ combined factorially with five signal rates $(6,12,24$, 48$, and $96 \mathrm{sig} / \mathrm{h})$. A visual display consisting of a red and green light mounted on a vertical vector was used; red-onset and green-offset were critical signals. The probability of correct detections increased monotonically with increases in signal duration; a stable rate of nearly $100 \%$ detection was approached at signal durations of 4.0 and $8.0 \mathrm{sec}$, independently of signal rates. The likelihood of detection was enhanced by increases in signal rates only at the 0.5-sec duration with the green-offset critical signal. Response time to correct detections increased with time on watch, independently of signal rates and durations.

The duration and rate of critical signals are stimulus parameters that have been related to watchkeeping performances. In general, efficiency increases as rate is increased (Buck, 1966; Frankmann \& Adams, 1962; Jerison \& Pickett, 1963), and decreases as the temporal uncertainty of signals is increased (Smith et al, 1966). Watchkeeping efficiency also increases as the duration of the signal is increased (Adams, 1956; Baker, 1963; Fraser, 1957), over the small range of durations employed (cf. Jerison \& Pickett, 1963). The joint effects of rate and duration have not been studied. Thus, the present experiment was designed to measure the functional relations between watchkeeping performance on the one hand, and signal rates, durations, and their interaction, on the other.

\section{METHOD}

Each of 50 Ss (volunteers from enlisted men attached to the U.S. Army Medical Research Laboratory, Fort Knox, who had not previously participated in watchkeeping studies) sat alone in an experimental room and monitored a pair of red and green lights mounted at eye level, approximately 24 in. away. The green light was located directly above the red and was normally on;its of fset

Fig. 1. Per cent correct detections as a function of signal rate at each of five signal durations; red-onset and green-offset signals. was a critical signal. The red light was normally off and its onset was critical. A pushbutton was provided below each light for $S$ 's responses.

Five signal durations $(0.5,1.0,2.0,4.0$, and $8.0 \mathrm{sec}$ ) were combined factorially with five levels of signal rate $(6,12,24,48$, and $96 \mathrm{sig} / \mathrm{h})$ to provide a total of 25 experimental conditions. Each $\mathrm{S}$ participated in five $1-\mathrm{h}$ sessions, during which he experienced the same signal rate, but a different one of the five signal durations and, of course, both of the signal types (red-onset and green-offset). Ten Ss were assigned at random to each level of signal rate; the order of appearance of signal duration was varied at random for each $S$ across the five sessions in which he served. The statistical distributions of intersignal intervals for all levels of signal rate approximated the right-hand half of a normal distribution and were identical to those used previously (Smith et al, 1966). During each session, half of the signals appeared on each of the two display lights, but otherwise, the order of appearance of signals of the two different types was a random variable.

\section{RESULTS}

\section{Percentage of Correct Detections}

Mean percentages of correct detections are plotted in Fig. 1 for each of the five signal durations. In each panel, the data are presented as a function of signal rate with the type of signal (red-onset or green-offset) as the parameter.

The data of Fig. 1 indicate that the probability of correct detection, generally less than $25 \%$ at the 0.5 -sec duration, tended to increase monotonically with increases in signal durations. A $100 \%$ probability of detection was approached at durations of 4.0 and $8.0 \mathrm{sec}$. This trend appears to have been independent of both the signal rate and the type of signal.

Systematic differences between signal rates and types did occur at the briefest signal duration. In order to understand more clearly the nature of these differences, an analysis of variance was computed on arcsin transformation of the $0.5-\mathrm{sec}$ data. The results indicated that green-offsets were detected significantly more frequently than red-onsets $(F=24.54, \mathrm{df}=1 / 45, \mathrm{p}<.01)$, and that the interaction of rate with type was also significant $(F=3.18$, df $=4 / 45$, $\mathrm{p}<.05$ ). Apparently, the rate of signal presentation had no effect on the detection of red-onset signals, but the probability of detection of green-offset signals was significantly lower at $6 \mathrm{sig} / \mathrm{h}$ than at other (higher) rates of presentation.

Examination of the data obtained with durations of $2.0,4.0$, and $8.0 \mathrm{sec}$ revealed no tendency for performance to decline with time on watch under any combinations of signal rates and types. The percentages of

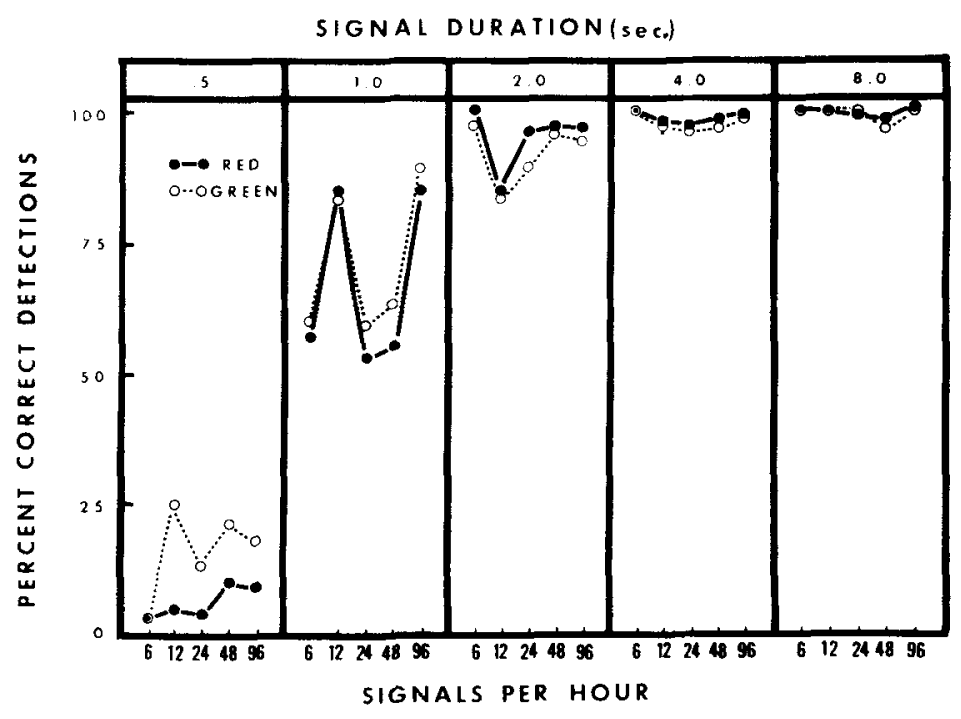




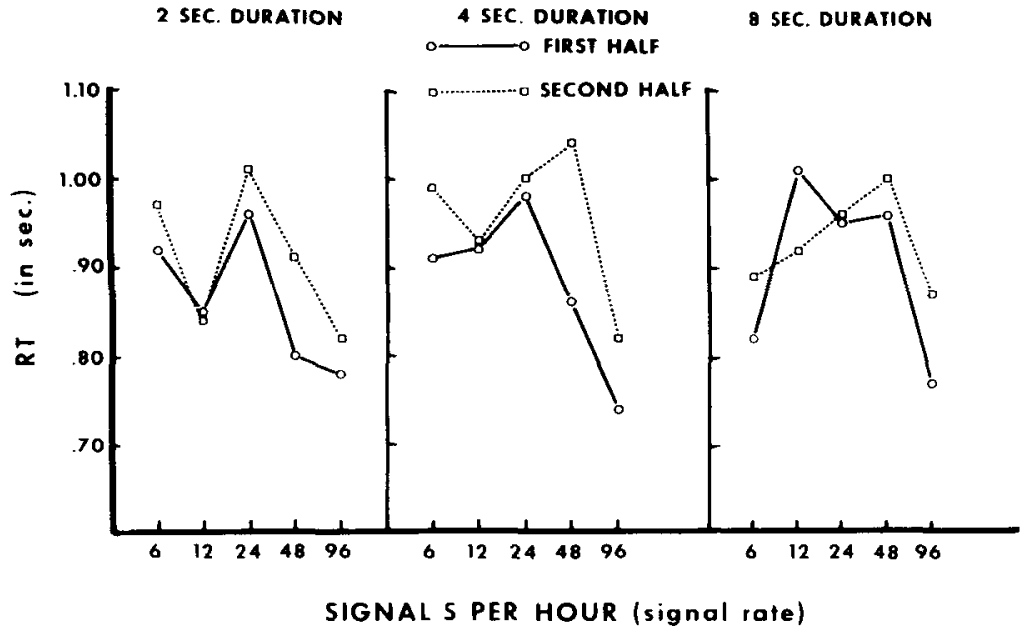

correct detections in some of the conditions at the two briefest durations were too low to warrant a similar analysis.

\section{Response Time (RT)}

For the reason indicated above, comparisons among RTs were limited to the data obtained at the three longest durations $(2.0,4.0$, and $8.0 \mathrm{sec})$. Median RTs were computed for each $S$ 's overall performance during the 1 -h watch under all combinations of signal rates, durations, and types. An analysis of variance indicated that the RTs to red-onset were significantly longer than to green-offset $(0.93$ and $0.86 \mathrm{sec}$, respectively; $F=27.77, \mathrm{df}=1 / 45, \mathrm{p}<.01$ ). None of the other effects was statistically significant.

It was not possible to present an equal number of the two types of signals during each $1 / 2-h$ vigil at the $6-\mathrm{sig} / \mathrm{h}$ rate, so signal type was not considered in testing for differences in RTs during the two halves of the watch. Instead, median RTs for the first and second $1 / 2-h$ periods were computed for each S's five sessions without regard to signal type. These data are presented in Fig. 2 for the three longest signal durations; in each panel, the data are presented as a function of signal rate with the time on watch (first vs second half) as the parameter.

An analysis of variance of the data of Fig. 2 indicated one significant main effect: RT was greater in the second $1 / 2-h$ period $(F=10.45$, df $=1 / 45, p<.01)$. No other effect was statistically significant.

\section{Type of Signal}

\section{DISCUSSION}

Green and red warning lights have been used in a watchkeeping or monitoring task in several studies as part of a multiple-task performance battery. In all of those studies, it has been found that mean normalized response times to correct detections of red-onset signals was faster than those of green-offset signals (Chiles et al, 1968). Yet, in a recent attempt to isolate the relative effects of color, position, and the onset or offset of such warning-light signals, the results seemed to contradict the previous findings-color was of no importance, position of little importance, and significantly faster RTs were obtained to offset rather than to onset signals (Warm et al, 1967). The statistically significant difference in RTs, briefer for green-offset and longer for red-onset signals in the present study, supports the latter finding. It is suggested that this represents a possible interaction of the stimulus parameters with a task parameter-the watchkeeping task's appearing alone or time-shared with other tasks as in the multiple-task performance battery. In any event, the differences in these findings are interesting and potentially important; they should be resolved.

\section{Signal Duration}

The results indicate that watchkeeping efficiency increases as signal durations are increased to a value between 2.0 and $4.0 \mathrm{sec}$. This is in general agreement with a prior report that signal detections almost always occur within $2 \mathrm{sec}$ in a short-term, free-response detection task (Egan et al, 1961). With the loosely coupled, free-scanning task used in the present study, it is apparent that variations in observing behavior did occur without adversely influencing detection probability when signal durations of $4.0 \mathrm{sec}$ or greater were used.

This may offer some very general support for certain theoretical positions. That is to say, in line with the theoretical formulations of Jerison and Pickett $(1963,1964)$ and the earlier proposal of Holland (1958), detection probability should be directly related to $S$ 's observing behavior. The present data could be used to provide estimates of the average rate of observing
Fig. 2. Response time as a function of signal rate at each of three signal durations; first and second halves of a 1-h watch.

and the average probability of a signal detection, given that both a signal and an observing response occur. For example, one such model could be constructed to predict detection probabilities of $.125, .750, .938$, .996 , and .999 for the five durations employed $(0.5,1.0,2.0,4.0$, and $8.0 \mathrm{sec}$, respectively). However, at the present stage, such a model would be nearly entirely gratuitous, and it would remain so unti further specifications could be made of the necessary assumptions regarding the duration and period of the implicit observing response and the weighting factors to be applied to these and other parameters that influence the performance.

\section{Signal Rate and Interactions}

In contrast to previous findings, the effects of signal rate were relatively trivial in this experiment. That is to say, rate effects were reflected by only one performance index (detection probability), and then only with one type of signal (green-offset) at the lowest signal duration $(0.5 \mathrm{sec})$. Where detection probability and signal rate have been found to be related, transient signals of 0.5 -sec duration or less have been used (Bowen, 1956; Deese \& Ormond, 1953; Jenkins, 1958; Kappauf \& Powe, 1959; Nicely \& Miller, 1957). Also, where RT and signal rate have been found to be related, essentially unlimited stimulus durations have been employed (Smith et al, 1966). The conclusion must be reached that the interactions of such task and signal parameters have important effects on watchkeeping performances.

The influence of signal rate on watchkeeping performance (cf. Smith et al, 1966) is complicated, and a valid psychophysics of watchkeeping will require additional considerations of the signal characteristics as well as the matrix of events in which they are embedded.

\section{REFERENCES}

ADAMS, J. A. Vigilance in the detection of low-intensity visual stimuli. Journal of Experimental Psychology, 1956, 52, 204-208.

BAKER, C. H. Signal duration as a factor in vigilance tasks. Science, 1963, 141, 1196-1197.

BOWEN, H. M. The appreciation of serial discrimination. In D. E. Broadbent, Perception and communication. New York: Pergamon, 1958. P. 115.

BUCK, L. Reaction time as a measure of perceptual vigilance. Psychological Bulletin, $1966,65,291-304$.

CHILES, W. D., ALLUISI, E. A., \& ADAMS, O.S. Work schedules and performance during confinement. Human Factors, 1968, 10, 143-196.

DEESE, J., \& ORMOND, E. Studies of detectability during continuous visual search. 
USAF WADC Technical Report No. 53-58, 1953.

EGAN, J. P., GREENBERG, G. Z., \& SCHULMAN, A. I. Operating characteristics, signal detectability, and the method of free response. Journal of the Acoustical Society of America, 1961, 33, 993-1007.

FRANKMANN, J. P., \& ADAMS, J. A. Theories of vigilance. Psychological Bulletin, 1962, 59 257-272.

FRASER, D. C. A study of vigilance and fatigue. In D. E. Broadbent, Perception and communication. New York: Pergamon, 1958. P. 112.

HOLLAND, J. G. Human vigilance. Science, $1958,128,61-67$.

JENKINS, H. M. The effect of signal-rate on performance in visual monitoring. American Journal of Psychology, 1958, 71, 647-661.
JERISON, H. J., \& PICKETT, R. M. Vigilance: A review and re-evaluation. Human Factors, 1963 $5,211-238$.

JERISON, H.J., \& PICKETT, R.M. Vigilance: The importance of the elicited observing rate. Science, 1964, 143, 970-971.

KAPPAUF, W. E., \& POWE, W. E. Performance decrement at an audio-visual checking task Journal of Experimental Psychology, 1959, 57 , 49-56.

NICELY, P. E., \& MILLER, G. A. Some effects of unequal spatial distribution on the detectability of radar targets. Journal of Experimental Psychology, 1957, 53, 195-198.

SMITH, R. P., WARM, J. S., \& ALIUISI, E. A. Effects of temporal uncertainty on watchkeeping performance. Perception \& Psychophysics, 1966, 1, 293-299.

WARM, J.S., LOEB, M., \& ALLUISI, E. A. Effects of color, relative position, and the onset or offset of signals in a watchkeeping task. Psychonomic Science, 1967, 9, 95-96.

\section{NOTES}

1. Supported in part by the U.S. Army Medical Research and Development Command, Department of the Army, under Research Contract No. DA-49-193-MD-2567, "Behavioral Effects of Infectious Diseases," and by Amy THEMIS Contract No. HC19-69-C-0009, "Studies of Performance Assessment and Enhancement." The authors are indebted to Clay Copeland and to Carl Guthrie for technical assistance.

2. Address: Performance Research Laboratory, University of Louisville, Louisville, Kentucky 40208.

(Accepted for publication May 12, 1969.) 